\title{
Entre a Inclusão e a Democracia Digital: a atuação do Estado e do terceiro setor em comunidades pobres da Região Metropolitana do Recife
}

\author{
Jonatas Ferreira $^{*}$ \\ Maria Eduarda da Mota Rocha*
}

\begin{abstract}
Resumo A acumulação histórica de capitais econômicos e culturais vem determinando padrões diferenciados de acesso à revolução informacional. Em geral, esse problema tem sido tratado pelas políticas públicas a partir de uma série de conceitos que convergem para as idéias polares de 'exclusão' e 'inclusão digital'. A partir dessa perspectiva, a solução do problema da desigualdade se apresenta como um percurso que os atores precisam fazer de um lugar vazio, de uma tabula rasa, para outro de prosperidade, numa clara atualização da visão dos atores em posição subalterna como seres faltantes. Recentemente, surgiu uma proposta de estimular a democratização das tecnologias digitais não como forma de simplesmente suprir uma falta, mas como estratégia de empoderamento. Apesar disso, não há consenso com relação ao modo como a desigualdade digital deve ser tratada, se a partir de investimentos visando à inclusão, se a partir de investimentos que capacitem camadas pobres da população a interferir na vida social em sentido amplo. Com base em pesquisa realizada em 8 instituições, mapeamos iniciativas de inclusão digital e analisamos como essas duas visões se traduzem em sua prática.
\end{abstract}

Palavras-chave inclusão digital; democracia; desigualdade.

\section{Between digital inclusion and digital democracy: state and third sector action in poor communities in the metropolitan area of Recife}

\begin{abstract}
The historical accumulation of economic and cultural capitals has been determining unequal patterns of access to the informational revolution. In general, public policies deal with this problem by recurring to concepts that converge to the polar ideas of "digital divide" and "digital inclusion". From this perspective, the solution to the problem of social inequality is presented as the trajectory that social actors need to undertake from an empty space, from a tabula rasa, to another of prosperity - a clear actualization of the perception of social actors in a subaltern position as lacking beings. More recently, a proposal for stimulating the democratization of ICTs has emerged, that is, not simply intending to fill in a gap, but sustaining
\end{abstract}

\footnotetext{
* Doutor em Sociologia pela University of Lancaster e professor adjunto do Programa de Pós-Graduação em Sociologia da Universidade Federal de Pernambuco (UFPE). Endereço postal: UFPE, Centro de Filosofia e Ciências Humanas, Departamento de Ciências Sociais, Av Acadêmico Hélio Ramos, s/n, Cidade Universitária, Recife, Pernambuco, Brasil, CEP. 50670-901, telefone (81) 32718285 e e-mail ferreirajonatas@uol.com.br

** Professora do Programa de Pós-Graduação em Sociologia da Universidade Federal de Pernambuco (UFPE). Endereço postal: UFPE, Centro de Filosofia e Ciências Humanas, Av. Acadêmico Hélio Ramos, s/n, Cidade Universitária, Recife, Pernambuco, Brasil, CEP. 50670-901, telefone: (81) 21268260 e e-mail me.rocha@uol.com.br
} 
the necessity to develop strategies of empowerment. Despite this, there is no agreement on how digital inequality has to be dealt with, whether by investments aiming at social inclusion, or by investments that would enable poor layers of the population to intervene in social life in a broader sense. Based on interviews in 8 institutions, this paper maps out initiatives of digital inclusion and analyzes how these two views are translated in practice.

Keywords digital inclusion; democracy; inequality

\section{Introdução}

$\mathrm{Na}$ análise da desigualdade, as ciências sociais têm operado ao longo dos anos vários recortes, tais como renda, etnia, acesso ao trabalho, participação política. A partir da segunda metade do século XX, com o surgimento das novas tecnologias de informação e comunicação, especificamente computadores pessoais, Internet, mecanismos portáteis de armazenamento de dados, como pendrives, ipods, CDs regraváveis, entre tantas outras possibilidades postas pela tecnologia digital, uma nova forma de desigualdade surgiu. A acumulação histórica de capitais econômicos, culturais e sociais dos diversos atores sociais, como era de se esperar, vem determinando padrões qualitativamente diferenciados de acesso a estes recursos. Não parece casual, portanto, que em 2007 apenas 24\% dos domicílios brasileiros tivessem computador desse total, apenas 3\% representavam domicílios com renda até $\mathrm{R} \$ 380$, valor que alcança os $72 \%$ quando consideramos domicílios com renda igual ou superior $\mathrm{R} \$ 3.801$. O acesso à Internet traz à tona uma realidade ainda mais constrangedora: apenas $1 \%$ das famílias que sobrevivem com até um salário mínimo tinham acesso à grande rede. Em geral, esse problema tem sido tratado pelas políticas públicas a partir de uma série de conceitos que convergem para as idéias polares de 'exclusão' e 'inclusão digital'. O ponto de partida desse tipo de abordagem é a idéia de digital divide, tal como formulada pela National Telecomunications and Information Administration, ainda na década de 90. A partir dessa perspectiva, a solução para o problema da desigualdade se apresenta como um percurso que os atores precisam fazer de um lugar vazio, de uma tabula rasa, para outro de prosperidade, numa clara reatualização da visão dos atores em posição subalterna como seres faltantes.

Ora, esse tipo de visão tem uma penetração significativa nas ciências sociais, bastando considerar a maneira como a tradição marxista, mas não apenas ela, percebeu ao longo dos anos o papel de forças sociais não diretamente ligadas ao processo produtivo. Visão semelhante dos mais pobres como "despossuídos" aparece na idéia bourdiana de "arbitrário cultural", em que as práticas de consumo dos dominados são avaliadas sempre em função de uma hierarquia unificada cujo cume e eixo moral são necessariamente os gostos das classes dominantes. Em função deles as práticas culturais subalternas aparecem como imitações mal-sucedidas. É certo que tal perspectiva pode ser contrastada com propostas mais matizadas, como a de Alba Zaluar, ou a de Vera Telles e sua conceituação da pobreza como "experiência da liminaridade", em que o esforço para superar uma definição puramente negativa da pobreza como falta não flerta com uma visão populista muitas vezes subjacente à celebração das competências das classes dominadas. Críticos das implicações políticas trazidas pela idéia de exclusão digital, tais como Mark Warshauer, Henry Jenkins ou Jeffrey Young ${ }^{1}$ acreditam que a "retórica da exclusão digital

\footnotetext{
${ }^{1}$ Young (2001) cita Jenkins.
} 
mantém aberta a divisão entre usuários de ferramenta civilizados e não usuários incivilizados. Bem intencionada como iniciativa política, ela pode propiciar a marginalização e ser fonte de privilégios em seus próprios termos". Ainda assim, no tratamento conceitual e político da desigualdade digital, a idéia de "exclusão" continua presente.

Entretanto, uma proposta diferente tem surgido, sobretudo entre organizações nãogovernamentais: estimular a democratização das tecnologias digitais não como uma forma de simplesmente suprir uma falta, mas como uma estratégia de 'empoderamento' dos atores a partir de suas próprias potencialidades. Apesar desse esforço, o terreno em que se busca enfrentar a desigualdade ainda é tenso: quer entre organizações não-governamentais, quer em instituições públicas ainda não há consenso com relação ao modo como a desigualdade digital deva ser tratada. De um lado, pensa-se em investimentos sociais e econômicos capazes de incluir atores em posição desfavorecida (vale dizer, em falta) no que tange às tecnologias de informação e comunicação - sem que competências culturais, educacionais e políticas sejam analisadas. De outro, propõe-se que estes recursos deveriam ser mobilizados a partir da premência que haveria em democratizar este acesso. Nesse caso, a desigualdade digital não poderia ser tratada apenas sob a ótica da "transmissão de conhecimentos" básicos que adaptem os atores ao mundo do trabalho, por exemplo, mas que os capacitem a interferir neste horizonte que em grande medida continua aberto.

A luta desses atores contra a desigualdade digital pode ser compreendida também à luz do contraste entre suas práticas e o "monopólio da fala" pelos meios de comunicação de massa. O surgimento de TICs digitais, sobretudo a Internet, deu margem a um grande otimismo quanto ao seu potencial de romper este monopólio, que pode ser pensado como a enorme assimetria existente entre os controladores dos grandes veículos de comunicação e o seu público. Nas últimas décadas alguns teóricos enfatizaram o potencial de emancipação das redes digitais de comunicação. Esse potencial, no entanto, parece longe de ser realizado. Nenhuma inovação tecnológica se produz num vazio histórico, social e cultural.

Cabe refletir empiricamente acerca das práticas que vem orientando os esforços públicos e de entidades do terceiro setor no sentido de favorecer a inclusão (ou democratização) das tecnologias de informação e comunicação em populações pobres. Nosso trabalho pretende mapear as iniciativas dessas instituições e organizações na Região Metropolitana do Recife e mostrar como tem se dado o embate entre essas duas visões. Com base em pesquisa exploratória realizada em 8 instituições do serviço público e do terceiro setor, e tendo como foco analítico sua atuação no que diz respeito a projetos de inclusão/democratização digital, constatamos alguns problemas que merecem discussão: a fragmentação das iniciativas; a dificuldade de articulação entre os diferentes atores e as perspectivas filosóficas que orientam suas intervenções, a descontinuidade das fontes de financiamento, a concorrência pelos recursos. Na dinâmica concreta dessas iniciativas, percebemos como a tensão entre concepções de democracia/inclusão digital se traduz em um desajuste entre as iniciativas políticas não formais e as estruturas formais de poder político e econômico.

A reflexão que propomos é uma iniciativa no sentido de qualificar a discussão sobre desigualdade digital num terreno político mais amplo do que geralmente ela tem sido concebida. Acreditamos que as intervenções públicas e do terceiro setor nessa realidade poderiam se beneficiar de trabalhos como este. Nos tópicos que se seguem procuramos: i. localizar a discussão acerca do acesso desigual às tecnologias de informação no contexto mais amplo da reflexão acerca da desigualdade social. De modo breve discutimos a pertinência de se pensar esse problema partindo dos pares inclusão-exclusão social; ii. no tópico seguinte, expomos os resultados que obtivemos até agora com a pesquisa exploratória realizada com dirigentes de 
instituições responsáveis por projetos de democratização das tecnologias de informação e comunicação; iii. no terceiro e último tópico esboçamos uma síntese de nossas conclusões até o momento.

\section{Acerca da desigualdade e inclusão social}

A noção de "inclusão digital" repõe uma visão corrente no Brasil, segundo a qual a pobreza é uma paisagem a ser conquistada pela modernização, apesar de todas as evidências de que a intensa industrialização vivida pelo país na segunda metade do século passado não baniu a precariedade do horizonte de vida de um amplo contingente da população. Repete-se, a respeito das tecnologias digitais, a mesma armadilha que Vera Telles (1992) havia detectado na conceituação da pobreza como o mero sinal de uma ausência: o esvaziamento da dimensão política do problema. Classificando os sujeitos a partir de uma privação material, é possível simplificar as raízes e conseqüências da desigualdade como o transpor de uma fronteira entre os que estão "dentro" e os que estão "fora".

Se, por um lado, o tema da desigualdade parece estruturar o esforço das ciências sociais desde a contribuição de seus precursores, passando pela sociologia clássica, parece-nos que ele esteve por muito tempo relacionado à idéia de pobreza como privação de capacidades. Poderíamos dizer que foram necessários quase cem anos para que as ciências sociais pudessem relacionar a questão da desigualdade ao tema da diferença. O motivo para esse aparente descuido parece evidente. Ora, desde os primeiros esforços feitos no sentido de uma reflexão científica acerca da sociedade o tema da diferença esteve associado ao Antigo Regime. Se tomarmos o Espírito das Leis como exemplo, esse livro seminal, lá encontraremos uma associação que marcará profundamente a emergência das ciências sociais. Se a república é ali concebida como o espaço da igualdade e a tirania como espaço do medo (ou do terror), a monarquia funda-se na diferença. Honra, distinção, diferença, portanto, são os valores sobre os quais a monarquia legitima seu governo - valores em oposição aos quais o Iluminismo proporá um novo modelo de sociedade. Retomando as lições de Montesquieu, Hannah Arendt observa: "A experiência fundamental nas monarquias, assim como nas aristocracias e outras formas hierárquicas de governo, é sermos diferentes uns dos outros por nascimento e, por conseguinte, nos empenharmos em nos distinguir, em manifestar nossa distinção natural ou social" (Arendt, 2005, p. 114). Por muito tempo, o tema da diferença, à crítica ao ideal iluminista da igualdade, foi associado a um pensamento aristocrático, como pode ser depreendido, por exemplo, da recepção hegemônica que recebe o pensamento nietzscheano.

No conjunto do pensamento social que se origina no final do século dezoito o tema da desigualdade se imporá sobre o da diferença. Ninguém haveria de negar, por exemplo, a importância que uma obra como o Discurso sobre a Origem da Desigualdade entre os Homens teve na definição de alguns contornos importantes da reflexão antropológica, sociológica e política. Relações entre desigualdade, propriedade e racionalização da vida, por exemplo, ali exploradas de forma engenhosa, provarão ser de grande influência na obra de vários cientistas sociais.

O marxismo constitui uma referência central para entendermos esse tipo de limitação - embora ela não se limite, evidentemente, a esse campo teórico. Tomemos emprestada uma análise que se tornou conhecida no Brasil. Em A Máquina da Revolta, Alba Zaluar reconstitui a trajetória do 
discurso da exclusão nas ciências sociais - o que, a nosso ver, coincide com a ausência de uma reflexão sistemática acerca das relações que existem entre desigualdade e diferença. Não é fortuito que o pensamento marxista resista em atribuir agência política ao lupemproletariado precisamente por considerá-lo como destituído, como faltante. Fundada na categoria trabalho, a análise marxista procura no mundo produtivo a chave para entender os processos de mudança social: todo segmento da população que estiver à margem do mundo do trabalho seria desprovido de condições elementares do exercício da cidadania. Em outras palavras, herdeiro da economia política inglesa, de compreensão do trabalho industrial como fonte de riquezas, o marxismo entende a produção da pobreza a partir desta mesma lógica. Ao fazê-lo, entretanto, Marx incorpora em seu corpus teórico uma atitude francamente negativa com relação a classes sociais cujo trabalho não fosse considerado produtivo nos termos da lógica e da dinâmica da economia industrial - e influencia um espectro considerável de pensadores ${ }^{2}$. Por isso, é fácil para ele concluir no Dezoito de Brumário, por exemplo, que o Lumpen vive da "mão para a boca" e que, portanto, seus problemas existenciais, culturais e políticos estariam reduzidos à sobrevivência física. A defesa da lógica produtiva do trabalho industrial também suscitou na teoria econômica e na sociologia clássica uma atitude preconceituosa com relação aos camponeses, mas sobretudo com relação ao setor de serviços - objeto, também, do humor terrível e brilhante de Jonathan Swift ${ }^{3}$.

Mesmo Pierre Bourdieu (1983), cuja obra esforça-se por ampliar a compreensão da luta entre os diferentes grupos para além da esfera econômica, flerta com a idéia de que a condição dos subalternos é caracterizada por uma despossessão. Os estilos de vida das classes populares, ele argumenta, é o resultado de uma combinação entre o reconhecimento dos valores dominantes e a ausência dos meios de realização desses valores. No campo cultural, os grupos da base da pirâmide se vêem privados de competência para a apropriação simbólica, assim como são desprovidos dos meios para a apropriação material no campo econômico. Se, por um lado, essa abordagem tem o mérito de assinalar os processos de violência simbólica envolvidos na aceitação de um arbitrário cultural dominante, por outro lado, tende a conceber as lutas sociais bem-sucedidas como uma translação entre uma dada configuração do campo e outra em que os outsiders se convertem nos novos estabelecidos. Nesses termos, a possibilidade de pensar uma mudança na lógica de funcionamento dos campos é muito reduzida.

A influência desse modo de pensar nas ciências sociais brasileiras é notável: em geral, a pobreza é percebida como a força conservadora que impede a sociedade brasileira de alcançar a plenitude da condição moderna e democrática. Sobre a forma de uma predisposição para aceitar formas políticas autoritárias (tais como o coronelismo ou o populismo) os pobres são, por definição, faltantes e entraves ao progresso.

Em sua tese de doutoramento, Marcia Longhi (2008) reconstitui os elementos através dos quais os jovens pobres são estigmatizados na sociedade brasileira. Um desses elementos, como era de se esperar, é a identificação destes com o lugar onde moram. Longhi observa uma oposição entre, por um lado, "a 'cidade' representando o 'progresso' e a favela, o 'atraso"'. E conclui citando Zaluar e Alvito (1998, p. 15), para quem "a favela e seus moradores foram, nos diferentes momentos históricos, construídos como o outro, um espelho invertido do 'tipo de identidade de cidadão urbano que estava sendo elaborada, presidida pelo higienismo, pelo desenvolvimentismo ou, mais recentemente, pelas relações auto-reguláveis do mercado e pela

\footnotetext{
${ }^{2}$ Ver, a esse respeito, por exemplo, Schwartzman (2004)

${ }^{3}$ Embora cáustico com respeito ao próprio mundo industrial (como é evidente sempre que lemos sua 'Modesta proposição para impedir as crianças pobres da Irlanda de ser um fardo para seus pais ou para seu país e torná-los úteis ao público'), sua má vontade para com o setor de serviços de seu tempo é antológica, como fica claro em 'Instrução aos empregados domésticos'.
} 
globalização"”. É comum encontrarmos em programas governamentais, em projetos sociais levados a termo por grandes organizações, um mesmo discurso de que é preciso dar trabalho, educação, diversão, arte aos jovens pobres como forma de conter o seu trânsito perigoso entre aqueles dois espaços. É preciso ocupá-los para que eles não carreguem a carência, a falta e a violência que lhes é associada dos espaços pobres, atrasados, para os espaços civilizados e modernos.

Seguindo essa linha de raciocínio, é possível dizer que as novas tecnologias têm sido objeto de uma disputa que alcança a própria lógica de sua utilização. É evidente que uma leitura breve nas estatísticas acerca dos obstáculos que se colocam ao ingresso do Brasil na "sociedade de informação", haverá de constatar que as desigualdades regionais ${ }^{4}$, de renda, de acesso à educação coincidem com as áreas onde tais obstáculos são mais marcantes. Em 2005, utilizando dados do Censo Demográfico e da Pesquisa Nacional por Amostra de Domicílios (2002), Sérgio Amadeu da Silveira constatava essas desigualdades no que dizia respeito: ao número de hosts nacionais, teledensidade (número de telefones por habitante), ao número de usuários da Internet, ao acesso a banda larga etc. em comparação com o resto do mundo. Sua necessária análise de nossas carências prossegue constando que o Censo Escolar de 2000 apontava para uma situação preocupante: apenas $56 \%$ dos alunos matriculados no ensino médio tinham acesso a laboratórios de informática, percentual que despencava para $22 \%$ quando focávamos o ensino fundamental e um percentual ainda menor (19\%) quando considerávamos o acesso à Internet. Diante desse quadro, fácil concluir que nosso grande problema seria o acesso a equipamentos eficientes e banda larga, por exemplo. Uma outra informação, presente no mesmo artigo, no entanto, passa quase despercebida:

É importante alertar que, mesmo possuindo conexão e computadores, várias escolas sem uso, em geral, pela falta de professores e pela ausência de uma política educacional de uso da Internet como uso pedagógico e de reforço à pesquisa escolar. Muitas salas de informática ficam trancadas e acabam sendo alvo de sucateamento e furto de equipamentos. (SILVEIRA, 2005, p. 463)

Em nosso entender, essa que se apresenta como comentário de passagem acerca daquilo que incorporamos da literatura norte-americana como "digital divide", ou "exclusão social", na verdade é um aspecto que mereceria uma atenção maior daqueles que definem políticas de inclusão social para este setor. Pois não basta constatar que esse problema demanda uma articulação entre o Estado e a sociedade civil; ou que o acesso à informação seja condição elementar de participação civil na sociedade contemporânea; ou que sem um aprendizado robusto das novas tecnologias de informação e comunicação, a desigualdade social será não apenas reproduzida, mas aprofundada. A própria idéia de inclusão digital merece uma atenção mais dedicada, sem a qual o sucateamento de equipamentos que poderiam se configurar como oportunidade política de acesso à cidadania digital nos chega apenas como uma evidência de que o esforço público necessita de uma racionalização mais efetiva.

Felizmente, parece que não apenas setores organizados da sociedade, como organizações do terceiro setor, mas cientistas sociais começam a despertar para a necessidade de pensar a questão

\footnotetext{
${ }^{4}$ Considere-se o mapa do backbone da Rede Nacional de Pesquisa, como ilustração. Parece evidente que as desigualdades sociais econômicas entre as regiões são espelhadas na distribuição de conectividade entre o centrosul, nordeste e norte, por exemplo, (ver http://www.rnp.br/backbone/index. php).
} 
da "exclusão/inclusão digital" no contexto mais amplo e profundo da democracia. Entre eles encontra-se Mark Warschauer, como pode constatar a leitura de Tecnologia e Inclusão Social: a exclusão social em debate (2006). Entre as críticas à noção de exclusão digital podemos destacar as seguintes: i. atribuir importância demasiada "à disponibilidade física de computadores e conectividade", em detrimento de questões relacionadas a "conteúdo, língua, educação, letramento, ou recursos comunitários e sociais" (p. 21); i. "uma divisão binária entre ter e não ter é [...] imprecisa e pode até ser fonte de privilégios, pois não é capaz de avaliar os recursos sociais que diversos grupos trazem à mesa"(p.22). Warschauer considera que o "estereótipo referente a grupos desconectados" pode "reforçar a estratificação social" (Ibid.) iii. Conceber as tecnologias de informação e comunicação como deus ex-machina dos antagonismos e problemas sociais. A todas essas ponderações, ele responde com a idéia de inclusão digital, noção que nos parece ainda inadequada diante das críticas formuladas. A idéia de inclusão também nos sugere um campo técnico e epistemológico consolidado, cabendo ao "outro" o papel do reconhecimento e do abandono de seu espaço de inserção cultural.

Por tudo isso, a diferença terminológica mapeada nesse estudo pode evidenciar uma disputa entre propostas de "inclusão digital" e de "democracia digital", na falta de melhor nome. Acreditamos que o aspecto político envolvido na desigualdade e na tentativa de sua superação fica melhor evidenciado desta maneira. E assim, no extremo do espectro político com o qual nos deparamos neste estudo, situam-se iniciativas em que o computador e a internet aparecem como instrumentos de uma inserção individualizada no mercado de trabalho, ecoando a noção de "empregabilidade" que localiza no esforço pessoal a causa do emprego e do desemprego. No outro extremo, estão práticas lastreadas em uma "concepção segundo a qual todas as formas de tecnologia de informação e comunicação podem ser subvertidas para atuarem fora do modelo e das formas do mercado, com vistas ao registro e comunicação de subjetividades e vivências não tematizados pela mídia comercial” (COSTA JR, 2008)

\section{‘Exclusão digital' na Região Metropolitana do Recife: algumas estratégias para combatê-la}

Iniciativa do Governo Fernando Henrique Cardoso, o primeiro esforço sistemático para compreender e propor soluções para o que se convencionou chamar de "exclusão digital" no Brasil apareceu no ano de 2000, no Livro Verde. Já naquele momento falava-se da urgência de encontrar "soluções efetivas" que possibilitassem a "diferentes segmentos sociais e regiões" terem acesso amplo à internet, combatendo assim a "info-exclusão" (p.26). A superação da "divisão digital" (tradução literal da expressão inglesa "digital divide") era compreendida como um entrave à plena realização da cidadania em uma sociedade que dependia cada vez mais da informação. Por esse motivo, aquele diagnóstico e proposta de ação sustenta que

\footnotetext{
"o conceito de universalização deve abranger também o de democratização, pois não se trata tão somente de tornar disponíveis os meios de acesso e de capacitar os indivíduos para tornarem-se usuários dos serviços da Internet. Trata-se, sobretudo, de permitir que as pessoas atuem como provedores ativos dos conteúdos que circulam na rede. Nesse sentido, é imprescindível promover a alfabetização digital, que proporcione a aquisição de habilidades básicas para o uso de computadores e da Internet, mas também que capacite as pessoas para
} 
a utilização dessas mídias em favor dos interesses e necessidades individuais e comunitários, com responsabilidade e senso de cidadania" (Livro Verde, 2000, p. 26).

Além disso, o acesso às tecnologias de informação e comunicação, e em especial à Internet ${ }^{5}$, era percebido como condição fundamental de desenvolvimento econômico do país e possibilidade de abertura de oportunidades de renda e emprego para amplas parcelas da população e em especial para as camadas pobres. Ou seja, "além de prover informações úteis ao cidadão, é possível oferecer-lhe serviços e informações capazes de auxiliar no funcionamento de seus negócios e nas tomadas de decisão, principalmente quando se trata de pequenas e médias empresas" (p. 28). O Livro Verde orientou as políticas de inclusão digital no país. Sua ênfase em inclusão para exercício da cidadania e inclusão para o desenvolvimento econômico ajudou a definir a pauta de financiamento de projetos de inclusão digital em todo o país. Já no Livro Branco, de 2002, que propõe os "caminhos" ao longo dos quais o ingresso na "sociedade de informação" seria viabilizado, uma ênfase clara na inovação é conferida. A ciência e a tecnologia deveriam fomentar nossa competitividade de inovar. No entanto, ao apresentar o livro, Fernando Henrique Cardoso ainda considera necessário empreender "uma verdadeira política de ciência da cidadania". Uma diretriz específica que viabilizaria essa boa intenção, no entanto, não é oferecida. Muito mais pragmática, a concepção de que as novas tecnologias são instrumento de desenvolvimento econômico, através do aumento da qualificação da mão-de-obra e da capacidade de inovação das empresas, dá o tom das políticas públicas para o setor desde então.

No ano de 2008, o Governo Lula contabilizava aproximadamente 20 programas responsáveis pela execução e apoio a ações de "inclusão digital", e que envolviam sobretudo os ministérios de ciência e tecnologia, educação e cultura ${ }^{6}$. Entre estes, destacamos o Programa nacional de Inclusão de Jovens (ProJovem), instituído pela lei no. 11.129, de 30.06.2006. Sua avaliação, finalizada em abril de 2008, de acordo com a revista A Rede, contabilizava a entrega de "1.687 laboratórios com dez computadores, impressora e roteador, para 58 cidades". O ProJovem, que tem como objeto pedagógico "o ensino fundamental, a qualificação profissional e a educação cidadã", orienta as ações de boa parte dos projetos do terceiro setor no campo da inclusão digital. Segundo Patrícia Cornils, a partir dessa avaliação constatou-se a "resistência das direções das escolas que cedem seu espaço ao projeto"

"A diretora... tudo fazia para dificultar (..) Muitos alunos desistiram porque discutiram com a diretora (...) e se transferiram para outro núcleo", diz um depoimento reproduzido no relatório parcial. Em escolas na cidade de São Paulo, diretores se queixaram dos alunos: "Demoramos anos para tirar essas

\footnotetext{
5 “Ao final dos anos 90, perdeu sentido criar redes de comunicação segregadas para voz (o terminal é o telefone, tarifado por assinatura e uso), dados (o terminal é o computador, tarifado por volume de dados) e imagem (o terminal é o televisor, na TV aberta, com receita oriunda de anunciantes). É possível fazer, com menor custo e crescente qualidade, tudo sobre IP. Significa que um único suporte tecnológico, a Internet, pode transportar, armazenar, redistribuir todas as mídias”. (Nelson Simões, 2008. 'Redes de pesquisa e Internet: uma introdução'. Politics, No. 1, p. 10 e11).

${ }^{6}$ São eles: Casa Brasil, Centro de Inclusão Digital, Computador para Todos, Centros Vocacionais Tecnológicos, Governo Eletrônico Serviço de Atendimento ao Cidadão (Gesac), Kitis Telecentro, Maré - Telecentros de Pesca, Observatório Nacional de Inclusão Digital, Pontos de Cultura - Cultura Digital, Programa Banda Larga nas Escolas, Programa Computador Portátil para Professores, Programa Estação Digital, Programa Nacional de Informática na Escola, Projeto Computadores para a Inclusão, Quiosque do Cidadão, Serpro Cidadão, Telecentros Banco do Brasil, Territórios Digitais, Telecentros de Informação e Negócios, Projeto Um Computador por Aluno.
} 
pessoas da escola, porque nos davam problema, agora vocês trazem de volta?" (CORNILS)

Depoimentos como esse sugerem que os projetos, com freqüência, esbarram em problemas muito antigos, como a estigmatização de estudantes de escolas públicas, vistos por alguns gestores como o estorvo que a sociedade depositou em suas mãos, e do qual conviria se livrar o quanto antes. Os valores, normas e representações pré-existentes em cada instituição onde um projeto desse tipo é implantado parecem condicionar de modo decisivo os seus resultados.

Um outro problema merece destaque e diz respeito à necessidade de articulação demandada pelo Programa. Enfatizamos esse aspecto por considerá-lo central para entendermos algumas dificuldades de democratização/inclusão digital que encontramos:

O ProJovem demanda uma grande articulação entre as secretarias de Educação, Assistência Social, Desenvolvimento Econômico e Emprego e gabinetes de prefeitos. Em São Paulo, essa articulação não aconteceu. Resultado: com uma meta auto-estabelecida de atender 30 mil alunos, a prefeitura tinha somente 1,5 mil em aula em junho, quando em uma reunião com o Ministério Público Federal acordou-se que a cidade devolveria ao Governo Federal R \$ 14,2 milhões dos R $\$ 37$ milhões destinados ao projeto e não utilizados. Em abril, os recursos haviam sido bloqueados por recomendação do Ministério Público. (CORNILS)

Talvez para driblar essa dificuldade, a Prefeitura do Recife, cujas ações de inclusão digital são apoiadas nas diretrizes e recursos do ProJovem, tem implantado infocentros em associações comunitárias, desvencilhando-se da responsabilidade de gestão e limitando-se a fornecer a capacitação dos monitores que atuam em cada comunidade, uma vez que os equipamentos e softwares livres são doados pelo Serviço Federal de Processamento de Dados (SERPRO).

Em iniciativas como essa, reaparece a ambigüidade no tratamento das novas tecnologias, celebradas simultaneamente como ferramentas para o desenvolvimento econômico e para a promoção da cidadania, embora essa última dimensão tenda a ser subsumida na primeira. $\mathrm{Na}$ pesquisa que realizamos com oito instituições públicas e do terceiro setor responsáveis por ações de ampliação do uso das novas tecnologias da informação e da comunicação em comunidades pobres do Recife, verificamos a sua distribuição em um espectro que vai de uma concepção de "inclusão digital", segundo a qual a meta é prover os "carentes" do conhecimento técnico necessário ao manuseio dessas tecnologias, com vistas, sobretudo, à sua inserção no mercado de trabalho, até uma concepção aqui denominada de "democratização digital", em que essas tecnologias são abordadas como instrumentos potenciais de emancipação, caso introduzidas em contextos favoráveis à formação ampla dos sujeitos.

Das iniciativas pesquisadas, bem próximas a uma concepção de "inclusão digital" baseada no uso das novas tecnologias para a inserção no mercado de trabalho, estão as experiências do Porto Digital e do Instituto Empreender. O primeiro é o articulador de um parque tecnológico composto por 106 empresas de vários portes, inclusive grandes multinacionais como Samsung e Motorola. Essas empresas recebem incentivos do governo estadual para operarem no bairro do Recife, no centro da cidade. Como "organização social" em estreita relação com o governo, o 
Porto Digital pode ser cobrado quanto ao caráter privatista de seus resultados. É sabido que, desde os anos 80, as empresas têm usado o "conceito" de "responsabilidade social" como recurso para compatibilizar seus ganhos corporativos e uma boa imagem perante a "opinião pública", o que as sucessivas crises econômicas e os custos da modernização capitalista no Brasil haviam tornado problemático (ROCHA). Também é corrente o uso dessa retórica da "responsabilidade social" para justificar o desmonte do Estado desenvolvimentista desde então.

Não surpreende, portanto, que o Porto Digital enverede por uma concepção semelhante, de "responsabilidade social" tanto mais por seu estatuto jurídico e político diferenciado em relação às empresas privadas. Como parte dessa preocupação, inicialmente, tentou-se implantar uma biblioteca com espaço multimídia para as crianças e jovens de uma comunidade pobre da cidade, a comunidade do Pilar, mas, sob alegação de falta de recursos, a iniciativa não foi adiante. Melhor sorte teve o Projeto Informar ${ }^{7}$, de capacitação de jovens em tecnologia voltada, sobretudo, à inserção no mercado de trabalho, financiado pelo Banco Mundial. Ele foi implantado em dois bairros pobres de Recife e Olinda e resultou na criação de uma empresa que hoje presta serviços de suporte técnico ao próprio Porto Digital. Um entrevistado, ligado à gerência de tecnologia social do Porto, evidencia a preocupação em realçar os ganhos coletivos de iniciativas como essa: "À medida que muitos jovens participantes do Projeto Informar ganhavam capacitação profissional e perspectivas de inserção no mercado de trabalho, as empresas participantes do projeto ganhavam mão-de-obra. Formavam-se, então, multiplicadores sociais onde antes havia jovens sem oportunidades, o crescimento da comunidade do Pilar era visto na organização comunitária mais sólida e esse crescimento da comunidade foi e ainda é visto, embora aos poucos, como um todo dentro da comunidade, envolvendo participantes e não participantes do projeto". O discurso e a prática mostram uma incorporação relativa da crítica à concepção de "inclusão digital", sob forma de desconfiança quanto ao caráter individualizado dos ganhos trazidos pelo projeto e na assunção da necessidade da organização comunitária para o sucesso do mesmo, algo que a experiência em bairros com níveis muito diferentes de mobilização parece ter ensinado aos gestores do Porto Digital.

Aqui vale ainda a pena constatar duas trajetórias distintas quanto ao seu sucesso dos esforços sociais desta instituição. Segundo o mesmo entrevistado, a diferença no nível de organização política das comunidades objeto da ação do Porto foram identificadas como elemento importante para explicar o maior êxito das iniciativas de "inclusão digital" junto à comunidade de Peixinhos, se a comparamos com a comunidade do Pilar. A comunidade de Peixinhos apresenta um nível de organização e de conquistas políticas consideravelmente superior à comunidade do Pilar. Efeito não pretendido dos projetos de revitalização do Recife Antigo, essa comunidade, de constituição recente, abriga a população ligada de uma forma ou de outra à antiga vocação boêmia do Recife Antigo. Projetos cujo êxito depende em grande medida da articulação de redes sociais e instituições tendem a encontrar sérias dificuldades quando essas redes são embrionárias ou extremamente fragmentadas.

Na mesma zona do espectro, próxima à concepção de "inclusão digital", estão as iniciativas do Instituto Empreender, uma organização da sociedade civil de interesse público - OSCIP responsável pelo projeto EnterJovem. A principal ação desse projeto é a "Empregabilidade e Tecnologia", voltada a capacitar e inserir no mercado de trabalho jovens entre 14 e 24 anos em situação de vulnerabilidade social, através de cursos de capacitação em informática, português, matemática, protagonismo juvenil, empreendedorismo, além de capacitações específicas demandadas pelas grandes empresas parceiras. O Instituto atua em diferentes bairros pobres da cidade, com o apoio de suas associações, implantando laboratórios e salas de apoio onde as

\footnotetext{
${ }^{7}$ Também promovido pelo $P D$.
} 
capacitações são realizadas. Ele também é parceiro do Governo do Estado e, por isso, pode dispor das escolas da rede pública de ensino. No Recife, o projeto surgiu em 2003 e capacitou mais de 4.200 jovens, dos quais 600 permaneceram no mercado de trabalho por um período superior a 1 ano e 3 meses, superando as suas próprias metas. Essas se definem como a inserção do maior número de jovens no mercado de trabalho o que, como vimos, é a forma mais corrente de conceber a "inclusão digital". Tal concepção está intimamente associada ao neoliberalismo, e ao abandono da perspectiva de desenvolvimento coletivo em prol da capacitação individual que o termo "empregabilidade" conota. Diante das desigualdades manifestas na estrutura social brasileira e respostas pela conjuntura de desmonte do Estado desenvolvimentista, a "inclusão digital" aparece uma resposta mais localizada e pontual.

A concepção de "inclusão digital" também está presente na Escola de Inclusão e Cidadania (EIC) de Caetés, um projeto que prevê a oferta de cursos de informática a jovens entre 12 a 28 anos, de comunidades carentes. Ele conta com nove educadores e seis turmas, mas, atualmente, encontra-se parado por falta de recursos para a manutenção dos equipamentos. O projeto surgiu de uma parceria com o Comitê para o Desenvolvimento da Informática (CDI), a quem a EIC deveria, em princípio, prestar contas regularmente. Mas a parceria viu-se ameaçada quando a EIC disputou e ganhou um edital do Governo do Estado, contornando a mediação do CDI e passando a concorrer com ele na captação de recursos. Apesar dessa descentralização na gestão e captação de financiamentos, o modelo empregado pela EIC é herdado do CDI e se caracteriza pela capacitação de usuários no manuseio das novas tecnologias com vistas, principalmente, à inserção no mercado de trabalho. É justamente a esse modelo que se opõem iniciativas agrupadas sob a rubrica da "metareciclagem", que tratam a apropriação da tecnologia como "ferramenta de expressão, de produção simbólica, de efetivo domínio do saber-fazer e adaptação à realidade local; enfim, como meio de construção de conhecimento dentro daquilo que pode ser chamado

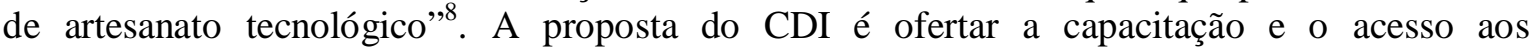
equipamentos em telecentros, nos quais os usuários têm contato com um conhecimento técnico estratégico para a obtenção de um emprego - embora a obtenção de tal conhecimento esteja associada, eventualmente, a uma discussão mais ampla de cidadania. Já a metareciclagem propõe a abertura de novas possibilidades de uso dessas tecnologias, a começar pela transformação do computador em instrumento de comunicação, para além de sua função de ferramenta de trabalho.

A apropriação, aqui, não diz respeito apenas ao conhecimento técnico necessário ao uso dos softwares e equipamentos produzidos pela grande indústria, mas se estende até à capacidade de entender o funcionamento das máquinas a ponto de ser possível reaproveitar o material "obsoleto" em novas composições. Além disso, deve contemplar também o uso de softwares livres, sem licenciamento, o que implica muito mais do que a eliminação do custo com a compra dos programas, uma vez que abre ao usuário mais habilitado a possibilidade de recriá-los segundo suas próprias necessidades. Nesse plano, estamos diante de uma disputa em torno de modelos de uso das novas tecnologias. De um lado, sua absorção pelo universo da produção e do trabalho; de outro, sua expansão até outras dimensões da vida. De um lado, a aceitação dos monopólios privados sobre os conhecimentos envolvidos nesse uso; de outro, seu questionamento em práticas que socializam tais conhecimentos para além do necessário à formação de mão-de-obra capacitada.

A concepção de que as novas tecnologias podem ser usadas para a democratização de recursos sociais estratégicos, como o poder de produzir e difundir representações sobre diferentes grupos sociais, também ecoa em duas iniciativas investigadas nessa pesquisa: a ONG Auçuba e o projeto de extensão Coque Vive, da Universidade Federal de Pernambuco. A Auçuba promove a

\footnotetext{
${ }^{8}$ Texto de apresentação do grupo Mutirão da Gambiarra. Apud COSTA JR., Luiz Carlos Pinto. Op. Cit., p. 6.
} 
formação de jovens através da produção de vídeos, fotos, textos, que funciona como a oportunidade para o desenvolvimento de habilidades técnicas, no manuseio dos equipamentos; políticas, de discussão de temas e problemas que os afetam; e humanas, de relacionamento e interação. Os produtos dessas experiências são veiculados nas comunidades pobres dos jovens participantes. Mais recentemente, a Auçuba foi indicada pela UNESCO para uma parceria com o Instituto Oi Futuro, da qual surgiu a escola Oi Kabum, de formação de jovens em fotografia, vídeo, design gráfico, computação gráfica, leitura e história da arte. Uma das responsáveis pelo projeto destacou o esforço dos alunos para montar, de maneira improvisada, um circuito de exibição dos produtos em suas comunidades de origem. Essa preocupação, assim como aquela de oferecer uma formação mais ampla, para além da qualificação técnica indica que a Auçuba guarda certa distância da concepção de "inclusão digital". Já mostramos como instituições que abraçam essa visão têm incorporado em seu discurso uma parte das cobranças que lhe são feitas em nome da "democratização digital". O fato de que o braço social da companhia telefônica $O i$ procurou o apoio de uma ONG com experiência em usos mais abrangentes das novas tecnologias, como catalisadoras de uma formação para a cidadania, pode demonstrar a intenção de diluir as resistências que um projeto concebido mais à distância das comunidades e do terceiro setor poderia provocar.

O Coque Vive é outra experiência próxima da "democratização digital". O Coque é um dos bairros mais estigmatizados do Recife e foi objeto de uma ação de extensão do Departamento de Comunicação da Universidade Federal de Pernambuco, voltada à formação dos jovens locais em oficinas de crítica às mídias, notadamente às representações preconceituosas sobre os moradores do bairro, e de produção de textos e fotografias em que outras representações pudessem ter lugar. A partir dessa ação, os alunos do curso de Comunicação articularam-se a ONGs, inclusive a Auçuba, à Igreja Católica e a ao Movimento Arrebentando Barreiras Invisíveis (MABI) de jovens da comunidade. Atualmente, está em fase de implantação a Estação Digital de Difusão de Conteúdos, uma plataforma para a produção de textos, vídeos, músicas e fotografia.

De modo geral, a "inclusão digital" aparece como o centro das preocupações das instituições públicas investigadas, o Serviço Federal de Processamento de Dados (SERPRO) e a Secretaria de Ciência, Tecnologia e Desenvolvimento Econômico da Prefeitura do Recife. Como vimos, o SERPRO fornece equipamentos e softwares livres para que a Secretaria implante "infocentros" nos espaços das associações comunitárias de bairros populosos da cidade. A iniciativa atende a propósitos diversos, tanto o de oferecer a oportunidade de um primeiro contato com os computadores, quanto a de inserir esse aprendizado como parte dos programas de "profissionalização" de jovens que a Prefeitura realiza, formando pedreiros, eletricistas, encanadores habilitados a fazer orçamentos em planilha eletrônica e a outros usos do computador. Djalma Paes, Secretário, esclarece: "A inserção no mercado de trabalho ocorre por meio da parceria que a Prefeitura tem com empresas. Estas solicitam alguns estudantes do projeto; em seguida, alguns deles são encaminhados e ficam empregados". Reforçando a proximidade com a concepção de "inclusão digital", a redução do índice de desemprego aparece como principal meta do projeto, embora a cidadania também seja mencionada de passagem. Como vimos, essa visão está posta já no âmbito federal, de onde provém os recursos e diretrizes que norteiam as iniciativas da Prefeitura, financiadas com recursos do ProJovem e do FAT. Mas ela é um pouco matizada pela incorporação de uma parte do discurso e das práticas dos movimentos sociais mais críticos ao modelo de "inclusão digital". Algo da concepção da metareciclagem virou política pública do Governo Federal, como parte do Programa Cultura Viva, do Ministério da Cultura, e suas práticas são estimuladas nos Pontos de Cultura. Assim, não é de causar espanto que o relatório de avaliação parcial (2007) do programa Casa Brasil formule do seguinte modo o conceito de inclusão digital: 
O conceito de inclusão digital é considerado de maneira ampliada para promover além da acessibilidade e a universalização do conhecimento, o desenvolvimento de habilidades para o uso instrumental, autônomo, crítico, criativo, inovador e sustentável das tecnologias da informação e comunicação; para a geração de oportunidades econômicas, culturais e sociais; para o desenvolvimento sustentável local e o fortalecimento das redes de relacionamentos; a participação democrática e cidadã pelo acesso a informações e serviços de egov, participação, representatividade e gestão comunitária. (BRANDÃO E SOUZA, 2007, p.16 e 17)

Apesar da preocupação com "desenvolvimento sustentável”, "fortalecimento de redes de relacionamentos", "participação democrática e cidadã" etc., o relatório organizado por Brandão e Souza constata que a área de gestão social é o pondo frágil do programa Casa Brasil. De qualquer forma, em graus e matizes diferentes, todas essas iniciativas se deparam com problemas referentes à necessidade e à dificuldade de articulação com os parceiros, com a comunidade e com os próprios beneficiários dos projetos. A concorrência pelos recursos e pelos usuários é comum entre as experiências investigadas, dificultando as parcerias firmadas entre entidades afins. Além de escassos, os recursos também são descontínuos, provenientes de parcerias e editais ou do financiamento de organizações do terceiro setor que eventualmente mudam suas prioridades - criança e adolescente, meio ambiente, empregabilidade etc. Segundo os gestores entrevistados, muitas iniciativas malogram devido à falta de recursos, como é o caso da biblioteca que o Porto Digital tentou implantar na comunidade do Pilar e a EIC Caetés, que se encontrava desativada pela mesma razão. Mas a disputa se estende até os alunos e, nesse caso, as iniciativas do terceiro setor são mais prejudicadas por que dificilmente têm como pagar bolsas. Os alunos evadem devido à necessidade de procurar trabalho ou à oportunidade de serem beneficiados por algum programa que ofereça remuneração, como os de qualificação profissional realizados no âmbito do ProJovem.

\begin{abstract}
"o maior empecilho, para os jovens que não seguem o curso, são as dificuldades enfrentadas em suas vidas. "O trabalho é um grande fator. As pessoas têm filhos, precisam sustentá-los e priorizam ganhar dinheiro, embora $85 \%$ tenha vínculo empregatício precário", explica ela. Cerca de $60 \%$ dos jovens do programa são pais ou mães, de acordo com Maria José. "A bolsa de $\mathrm{R} \$ 100,00$ mensais oferecida pelo projeto é importante para as pessoas estudarem, mas elas não podem se sustentar apenas com isso", constata. Outro motivo de evasão foi a migração, principalmente em direção a cidades nas regiões Norte e Centro Oeste. "Para minimizar o impacto desses fatores, criamos, no ProJovem Urbano, ciclos de seis meses. Se o jovem interromper o curso, pode retomá-lo a partir do ciclo concluído" (CORNILS).
\end{abstract}

A julgar pelos dados a que tivemos acesso, a evasão é maior nos projetos de "democratização digital". Mas todos, inclusive os voltados ao emprego, deparam-se com o problema da falta de sentido no uso das TICs para os fins propostos. A Secretaria de Desenvolvimento da Prefeitura do Recife assume a necessidade de "sensibilização para o uso do computador". O secretário apontou como um dos problemas o "desvirtuamento" do uso do computador pelos jovens, mais 
interessados em Orkut e jogos. Curioso que surja hoje uma farta literatura acerca da importância dos jogos eletrônicos como forma diferenciada de experiência do conhecimento: uma forma de conhecimento lúdica por definição e que propõe ao indivíduo uma experiência viva ainda que simulada dos conteúdos deste conhecimento. Muitos foram os filósofos e cientistas sociais que dedicaram em algum momento de sua trajetória um momento de reflexão aos jogos. No Verdade e Método, por exemplo, Gadamer propõe que o jogo é uma forma de conhecimento mais próximo da arte que da ciência. E se a ciência moderna propõe um modelo cognitivo que separa, distancia o sujeito de seu objeto de conhecimento, por isso atuando de modo a delimitar de modo claro esses objetos; a experiência do jogo funciona a partir de uma proximidade entre tais pólos. O jogar pressupõe envolvimento e tolerância com o fato de que a experiência que ele proporciona é indeterminada, aberta. Essa forma de cognição seria, portanto, muito mais próxima das experiências culturais contemporâneas (muito mais "rizomáticas" que "enraizadas") do que a fria objetividade científica. Não é gratuito, portanto, que o significado econômico dos jogos eletrônicos tenha ultrapassado a bilionária indústria do cinema como forma de entretenimento no mundo. Que os jovens se identifiquem com essa possibilidade de experiência e convívio na Internet deve ser visto como uma oportunidade a ser explorada, e não como um problema. Essa constatação, entretanto, coloca-nos uma vez nosso refrão: a própria concepção de exclusão/inclusão digital promove estereótipos que reforçam a desigualdade e nos impedem de perceber caminhos para a sua solução.

Uma ilustração simples desse tipo de sensibilidade. No projeto Coque Vive, a proposta de criar um jornal eletrônico ao final de um dos cursos de formação deu lugar a um mural porque os alunos constataram a maior eficiência desse recurso no seu meio social, no qual interessava para eles divulgar seus trabalhos. Diante dessa dificuldade, percebeu-se o desafio de uma articulação mais orgânica com a comunidade, de modo que as propostas incorporem os interesses que os próprios beneficiários reconhecem como tais. Por tudo isso, talvez a maior dificuldade para os projetos de democratização digital e, em menor grau, para os de inclusão digital, seja a de não ceder à solução mais simples de impor um modelo de uso das novas tecnologias sem considerar as competências e os interesses dos atores envolvidos.

\section{Considerações finais}

As TICs, ou seja, a comunicação mediada por computadores, a produção de vídeos, músicas, produção e emissão radiofônicas em formato digital etc., constituem um espaço técnico-social amplo e em processo de redefinição constante. Essa característica das TICs, longe de se dever ao seu caráter imaturo, parece ser a sua forma mesma de funcionamento. Trata-se de um espaço tecnológico que, por definição, é extremamente rizomático, o que abre espaço para a presença de concepções muito díspares sobre seu sentido e para articulações difíceis de prever. Muito do que tem sido produzido acerca de inovação tecnológica na sociedade de informação, aliás, aceita essa característica como algo dado. É isso, por exemplo, que subjaz ao privilégio conferido ao conhecimento tácito sobre o conhecimento codificado na literatura sobre inovação: uma atitude de abertura cognitiva e emocional ao novo significa aceitar esse caráter rizomático como horizonte cultural de nossos envolvimentos tecnológicos.

Não parece fortuito, portanto, que diversos grupos sociais vejam nessas tecnologias possibilidades bastante distintas, o que implica que uma discussão localizada no campo da cultura da informação tenha um potencial político polissêmico. Potencial que pode ou não se 
realizar efetivamente. Grupos indígenas, afro-descendentes, quilombolas, populações pobres das grandes cidades, devem não apenas ocupar um espaço tecnológico já existente, mas ajudar a constituí-lo. Nem sempre aquilo que as autoridades governamentais pensam que estão ofertando coincide com aquilo que esses grupos estão 'consumindo', ou dispostos a consumir. Neste sentido, chama a atenção iniciativas através das quais a cidadania pode encontrar canais de expressão e novas questões com as quais lidar. Iniciativas como a Rede Mocambo, a Metareciclagem, a produção e consumo de música na e pela Internet, a capacitação profissional, a construção de ferramentas que possibilitem o acesso de cegos à Internet, as amplas possibilidades de produção de textos, imagens e sons aproveitadas por experiências de comunicação comunitária, depõem acerca dessa polissemia.

Nosso estudo exploratório, entretanto, constata a delimitação dessas possibilidades em direção a duas preocupações básicas: i. a capacitação de populações pobres de modo a permitir-lhes o acesso a um mercado de trabalho no qual as tecnologias de informação e comunicação desempenham um papel central. Embora o discurso a esse respeito seja matizado com a preocupação de um retorno social de investimentos deste tipo para as comunidades onde as ações são realizadas, pode-se constatar o foco claro na empregabilidade dos indivíduos. Esse descolamento constitui fonte de tensão no que concerne à apropriação deste tipo de esforço pelas comunidades em questão. ii. a preocupação com a formação de uma consciência crítica e com a capacitação de grupos subalternos para sua auto-expressão e participação também nos âmbitos da cultura e da política. Vimos como instituições públicas, privadas e do terceiro setor interpretam e atualizam essas duas concepções.

Por vezes, os responsáveis pelas iniciativas de inclusão digital estão cientes da necessidade de inscrever o trabalho, o tema da empregabilidade, em um contexto mais amplo. Mas a própria idéia de cidadania é vaga e a tecnologia é sempre concebida como uma dádiva que visa a suprir uma falta. Mesmo consensual, a idéia de aprender TICs para ingressar no mercado de trabalho parece enfrentar resistências: falta de interesse da populações-alvo e evasão foram identificadas. Assim, parece lógico para um dirigente da secretaria de ciência e tecnologia do município que este aprendizado demande sempre uma etapa de "sensibilização" para a necessidade de uso do computador na sociedade contemporânea. Espera-se através deste recurso, obviamente, aumentar o interesse pelo uso de tecnologia. Não ocorre que a tecnologia em questão não é simplesmente algo definido, uma competência claramente descrita que se aprenderia, mas um horizonte tecnológico: o que a Internet e as tecnologias de informação e comunicação são é algo a ser definido constantemente nos envolvimento desses indivíduos com esses meios e com sua realidade.

Assim, mesmo esse trabalho cujo padrão vem sendo largamente definido por dinâmicas globais não pode ser pensado fora de um contexto cultural onde os indivíduos estejam inscritos. Veja-se, a esse respeito, a inadequação de muitos projetos ao capital cultural de seu público-alvo. Diante da constatação dos problemas de educação formal de muitos participantes de seus projetos de qualificação profissional, a Prefeitura do Recife criou um programa de reforço para eles através da Secretaria da Educação. Ao contrário do grande otimismo que visões mais ingênuas podem sustentar a respeito, principalmente nesses tempos de campanha eleitoral, as novas tecnologias não são um atalho para resolver os problemas educacionais do país. É fundamental, no entanto, concebê-las como parte de estratégias amplas que envolveriam a educação, a alfabetização de parcelas sem escolaridade, integrando-as, por exemplo, aos cursos noturnos nos quais se aprende a ler, escrever e interpretar.

Quanto à formação para a cidadania, constatamos que a participação dos movimentos sociais é aqui muito mais significativa. Auçuba, Instituto de Cegos, Coque Vive são exemplos. Essas 
organizações sociais buscam contribuir para que as tecnologias sirvam para viabilizar a expressão, o reconhecimento e a participação política. A Rede Mocambo, Queremos Voz, Central Única das Favelas, Metaciclagem, movimentos pelo software livre e pelo copy left, as novas tecnologias parecem dar vazão a uma forma diferenciada de ativismo que opera rizomaticamente, como fica muito evidente na Rede de Submidiologia ${ }^{9}$. Os resultados mais esperados aqui se traduzem no combate ao estigma, na crítica às representações correntes desses grupos, na recusa dos monopólios privados sobre o conhecimento e a cultura e, mais amplamente, no uso dessas formas de construção discursivas (jornais, blogs etc.) como meios de aprender conteúdos culturais outros, além daqueles relacionados às TICs. Herdeiros da virada político-cultural da década de 1960, esses ativistas tendem a manter distância das formas institucionalizadas da política, como os partidos e os sindicatos, mesmo correndo o risco de ver a suas ações perderem sua dimensão estratégica e se dispersarem em frentes muito fragmentadas. A articulação em rede parece ser uma tentativa de transcender os seus focos específicos de luta, embora o risco permaneça.

Mas o grande problema, tanto para os adeptos da "inclusão" quanto da democratização" digitais parece ser o de promover a apropriação significativa das TICs pelos sujeitos e comunidades. Para que as iniciativas tenham mais sucesso nesse quesito é necessário, em primeiro lugar, que deixem de lado a concepção aristotélica de técnica, segundo a qual ela é apenas um meio para um fim ou um fim em si. Os gestores públicos de tecnologia oscilam entre ver a tecnologia como meio, para possibilitar o acesso ao emprego, por exemplo, e como um fim em si, afinal estaríamos numa "sociedade da informação". Essas variações partem de uma mesma premissa: as tecnologias são um objeto desgarrado do sujeito. Mas se a tecnologia for pensada como um horizonte tecnológico (e aqui temos em mente o conceito fenomenológico de horizonte) onde se negociam, e entram em conflito, diferentes perspectivas culturais e políticas acumuladas e suas tensões e o chamado inescapável do futuro, talvez seja possível alargar as suas possibilidades de uso de maneira a contemplar as competências e os interesses dos usuários sem perder de vista finalidades que escapem a esses interesses e competências. Para isso, precisaríamos prestar mais atenção às novas formas de ativismo, em formas não convencionais de lidar com o conhecimento (tais como os jogos); naquilo que é importante para as comunidades e (obviamente) também às demandas da "sociedade de informação".

Artigo recebido em 17/11/2008 e aprovado em 16/03/2009.

\section{Referências}

ARENDT, H. A Promessa da Política. Rio de Janeiro, Editora Bertand-Brasil, 2005.

\footnotetext{
${ }^{9}$ Submidiologia é uma rede que abriga ativistas que denunciam o monopólio do conhecimento e da mídia pelas grandes empresas e que experimentam formas cooperativas de produzir e difundir cultura, sobretudo, através da internet, mas, também, através de encontros realizados periodicamente.
} 
BOURDIEU, P. Gosto de Classe e Estilo de Vida. In ORTIZ, Renato (org.) Pierre Bourdieu. Coleção Grande Cientistas Sociais. São Paulo: Ática, 1983.

BRANDÃO, M.F.R e SOUZA, P.C (Org.). Relatório Parcial de Avaliação Casa Brasil. MCT, 2007. Disponível em <http://www.casabrasil.gov.br/images/stories/relatóriofinalilustrado.pdf>

BRASIL. MINISTÉRIO DA CIÊNCIA E TECNOLOGIA. Sociedade de Informação no Brasil: Livro Verde. Brasília: Ministério da Ciência e Tecnologia, 2000

LONGHI, M. Navegando em seu Cenário: reconhecimento e consideração a partir da trajetória de rapazes de grupos populares do Recife. Recife, Editora da UFPE, 2008 (no prelo).

MARX, Karl. O 18 de Brumário e Cartas a Kugelmann. São Paulo, Paz e Terra, 1997.

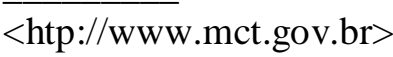

CORNILS, Patrícia. ProJovem dribla dificuldades In: A Rede. 20 Ago 2008. Disponível em <http://www.arede.inf.br/index.php?option=com_content\&task=view\&id=1505\&Itemid=474>. Acesso em 17/09/2008.

COSTA JR, Luiz Carlos Pinto. Potência e derrelição: uma análise da metareciclagem como política radical de mídia. Recife: mimeo, 2008.

ROCHA, Maria Eduarda da Mota. A nova retórica do grande capital: a publicidade brasileira em tempos neoliberais. Tese de Doutorado. São Paulo, Editora da USP, 2004

ROUSSEAU, J. J. Discurso sobre a Origem e os Fundamentos da Desigualdade entre os Homens. In Coleção os Pensadores. São Paulo, Abril Cultural, 1991.

. O Emílio ou da Educação. Rio de Janeiro, Editora Martins Fontes.

SCHWATZMAN, Simon. 2004. Pobreza, Exclusão Social e Modernidade: uma introdução ao mundo contemporâneo. São Paulo, Augurium Editora.

TELLES, Vera da Silva. A Cidadania Inexistente: Incivilidade e Pobreza - Um Estudo sobre Trabalho e Família na Grande São Paulo. Tese de Doutoramento apresentada no Departamento de Sociologia da USP, 1992.

WARSCHAUER, M. Tecnologia e Inclusão Social: a exclusão digital em debate. São Paulo, Editora SENAC, 2006.

YOUNG, Jeffrey. Does 'Digital Divide' Rhetoric Do More Harm Than Good? In. The Chronicle of Higher Education, Information Technology. 09 Nov 2001. Disponível em <http://chronicle.com/free/v48/i11/11a05101.htm>. Acesso em 20/09/2009.

ZALUAR, A, A Máquina da Revolta. As Organizações Populares e o Significado da Pobreza. São Paulo, Editora Brasiliense, 1994. 